\title{
Investigating the utility of a high-temperature Thellier-style paleointensity experimental protocol
}

\author{
J. Michael Grappone ${ }^{*}$ (D) James M. Russell and Andrew J. Biggin
}

\begin{abstract}
High-quality data are vital to the research field of paleointensity, which has long suffered from poor-quality and/or sparse data. Previous paleointensity work has established that repeatedly heating specimens increases the opportunity for thermochemical alteration to decrease the reliability of paleointensity data. In addition, recent work has shown that repeatedly heating specimens in paleointensity experiments can also exaggerate the effects of non-ideal, non-single domain grains. Arai plots resulting from paleointensity experiments containing such grains are often curvilinear (two-slope) across most of the specimen's unblocking temperature spectrum, except in the temperature range nearest to the grains' Curie temperature. This study tests the following strategy to mitigate these effects: that of performing a Thellier paleointensity experiment using fewer temperature steps that are also concentrated at higher temperatures. For this purpose, we use natural specimens with well-constrained rock magnetic data from the Hawaiian Scientific Observation Hole $1(\mathrm{SOH} 1)$ drill core in paleointensity experiments with starting temperatures ranging from $200{ }^{\circ} \mathrm{C}$ to $500+{ }^{\circ} \mathrm{C}$. Those experiments that focused in on the portion of the unblocking temperature spectrum nearest the Curie temperature of the specimen ( $\mathrm{HiTeCT}$ ) had an exceptionally low success rate, whereas those with initial temperatures at comparatively moderate temperatures $\left(200-400^{\circ} \mathrm{C}\right)$ had high success rates $(\sim 70 \%)$. Thermochemical alteration was minimized with a start temperature of $400^{\circ} \mathrm{C}$, but the curvature of the Arai plots had no clear dependance on start temperature. We conclude herein that increasing the start temperature can help avoid the effects of low-temperature alterations. Additionally, we found that the approach of focusing in on the highest temperature range is not a feasible one to apply in paleointensity experiments, in general, and consider this likely to be a result of a lack of intermediate-temperature checks for alteration and insufficient independence of temperature steps.
\end{abstract}

Keywords: Paleomagnetism, Paleointensity, Methodology, Rock magnetism

*Correspondence: grappone@liverpool.ac.uk

Geomagnetism Laboratory, School of Environmental Sciences, University of Liverpool, Liverpool L69 7ZE, UK original author(s) and the source, provide a link to the Creative Commons licence, and indicate if changes were made. The images or other third party material in this article are included in the article's Creative Commons licence, unless indicated otherwise in a credit line to the material. If material is not included in the article's Creative Commons licence and your intended use is not permitted by statutory regulation or exceeds the permitted use, you will need to obtain permission directly from the copyright holder. To view a copy of this licence, visit http://creativecommons.org/licenses/by/4.0/. 


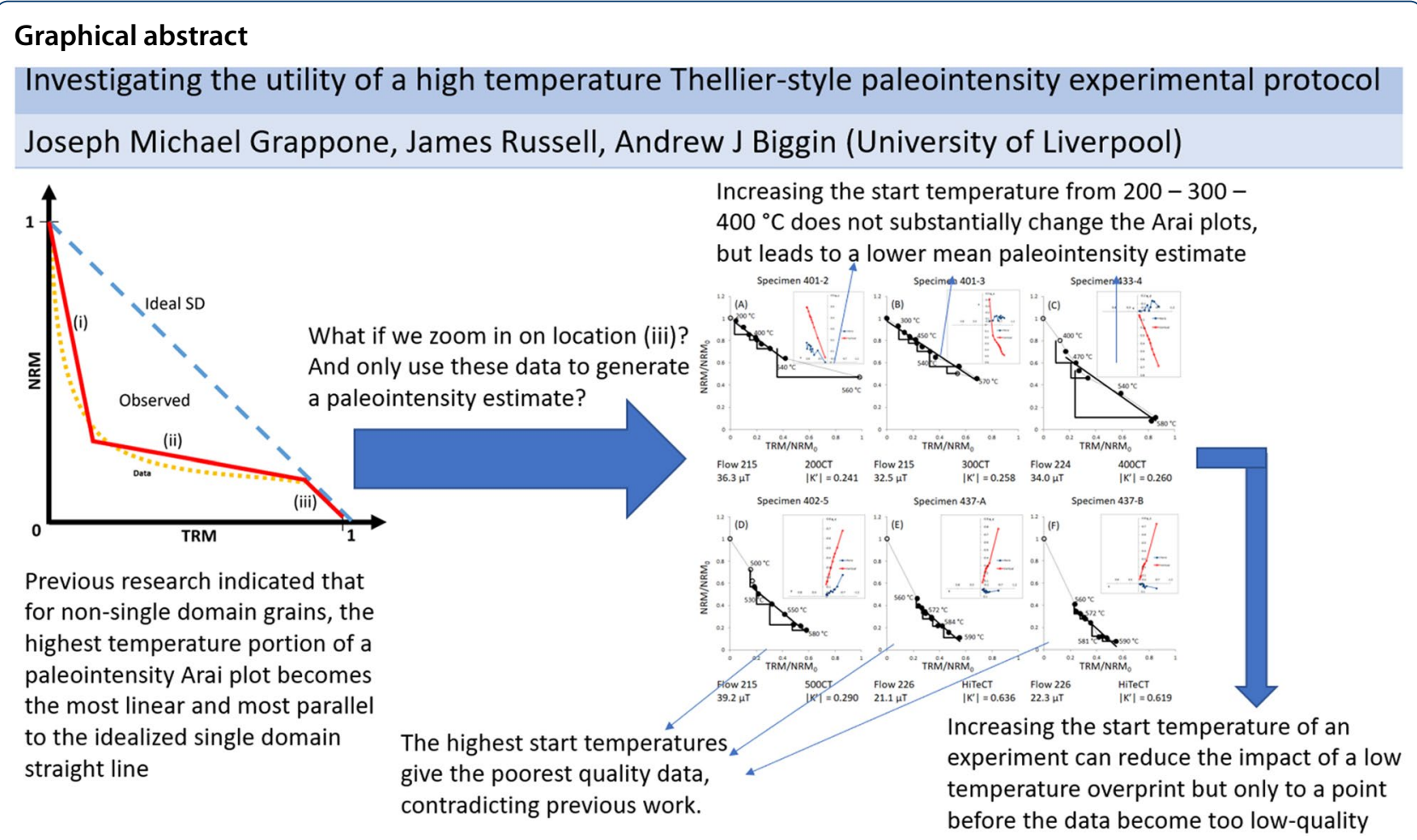

\section{Introduction}

Paleomagnetism provides a unique means to probe Earth's deep interior over the billions of years across which rocks preserve primary magnetizations. Estimates of the strength of the Earth's magnetic field (its paleointensity) are essential to understanding long-term changes in the geodynamo. Therefore, accurate and broad paleointensity surveys are needed across the entirety of the rock record.

Initially, just a single step was used to replace the specimen's magnetic field with a field of known strength (Koenigsberger 1936). Thereafter, the method was expanded to include multiple steps and a best-fit line for a more robust estimate (Thellier and Thellier 1959). Next, checks for thermochemical alteration (pTRM checks) were added because alteration may not always cause a sharp change in the slope of the Arai plot data [e.g., Coe (1967)]. Thereafter, checks for non-single domain behavior (pTRM tail checks) were added because their nonideal behavior can cause sagging (concave-up) curvilinear Arai plots (Riisager and Riisager 2001). The addition of each of these steps increased the required amount of time to complete the experiment, but aimed to improve the fidelity of the resulting data.

The problem with large magnetic grains stems from their non-unique lowest energy domain configurations.
Large grains contain multiple magnetic domains, whose domain walls deteriorate and then reform each time the grain is remagnetized [e.g., Butler (1992)]. These domain walls do not necessarily reform into the same configuration, so precisely replicating the previous domain state is nearly impossible. Absolute paleointensity methods require the excitement of magnetic grains to remove and replace their natural remanent magnetization (NRM) with a known field (Thellier and Thellier 1959), giving them a thermoremanent magnetization (TRM). Since multi-domain grains cannot necessarily be returned to the same internal domain wall configuration, the data extracted from paleointensity experiments containing multi-domain grains are, at best, not necessarily fully reproducible and, at worst, severely biased and unusable.

Hodgson et al. (2018) showed that repeatedly heating synthetic specimens containing interacting single domain or multi-domain (MD) grains can cause increased deviation from ideal single domain (SD) behavior. The deviation, in turn, causes an Arai plot to become curvilinear over the course of a paleointensity experiment, which is an issue that has been known for over 40 years (Levi 1977). Hodgson et al. (2018) used the Coe (1967) variant of the Thellier protocol, which consistently gives concave-up Arai plots (Nagata et al. 1963) when non-SD effects are strong (e.g., Shcherbakova et al. (2000)). The 
result can be a paleointensity overestimate if the lowtemperature portion of an Arai plot is used (Coe et al. 2004; Dunlop and Ozdemir 2001; Xu and Dunlop 2004) and an underestimate if the high-temperature portion of an Arai plot is used (Biggin and Thomas 2003; Dunlop et al. 2005; Shcherbakov and Shcherbakova 2001).

One of the major findings in Hodgson et al. (2018) was that the Arai plot straightened out in the temperature region approximately $20^{\circ} \mathrm{C}$ below a given specimen's Curie temperature. Their Fig. 12 is reproduced in Fig. 1.

In addition, Hodgson et al. (2018) showed non-SD effects can be reduced by minimizing the number of heatings and restricting the experiment to only temperatures near the Curie temperature $\left(\mathrm{T}_{\mathrm{C}}\right)$ of the specimens. The specimens in Hodgson et al. (2018) were artificially created from naturally occurring magnetite and oxyexsolved titanomagnetite. As a result, these specimens had well-defined Curie temperatures and rock magnetic properties, which made doing high-temperature paleointensity experiments relatively straightforward. This paper develops and tests the method proposed by Hodgson et al. (2018) using natural basalt specimens from the wellstudied Scientific Observation Hole (SOH1) bore hole from the island of Hawai' $i$.

In the purest form of Hodgson et al. (2018)'s method, only temperatures in the range $T \in\left[T_{C}-20, T_{C}\right]$ are used, and alteration checks are omitted to minimize the

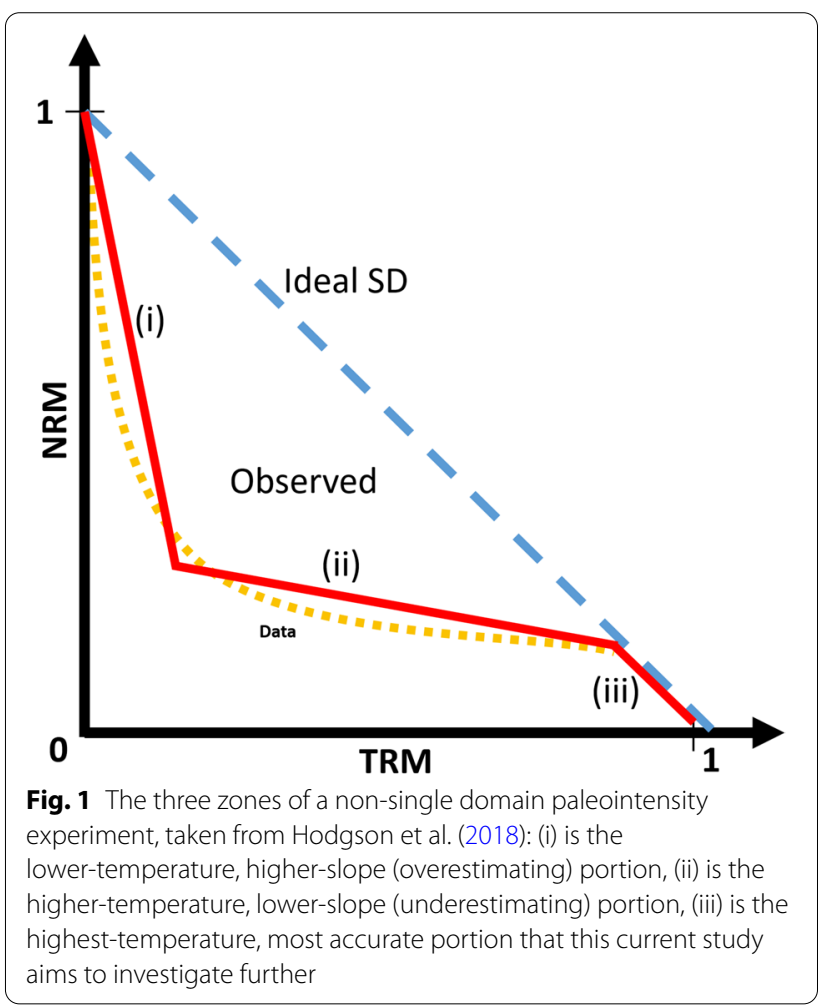

number of heatings. However, the lack of systematic pTRM checks means that alteration cannot be detected, which would limit the reliability-as expressed by, for example, the $\mathrm{Q}_{\mathrm{PI}}$ score (Biggin and Paterson 2014) of these experiments. This technique will be tested further herein by including systematic alteration tests (pTRM checks) in the experimental protocol.

The purpose of this current study is to investigate the aforementioned Hodgson et al. (2018) high-temperature paleointensity method by taking the Coe (1967) paleointensity method to its extreme. This study therefore undertook experiments with a range of initial temperatures, from a relatively standard $200{ }^{\circ} \mathrm{C}$ to a maximum of $560{ }^{\circ} \mathrm{C}$.

\section{Material}

For this study, 99 specimens were selected from 15 flows from the Scientific Observation Hole (SOH) 1 drill core (island of Hawai ${ }^{i}$ ) from the University of Liverpool's repository. The $\mathrm{SOH}$ drill core's basalts cover the 0-46 ka time range sampled across nearly 240 flows. All specimens used have had their rock magnetic properties reported in previous studies (Grappone 2020a; Grappone et al. 2020b; Gratton et al. 2005; Teanby et al. 2002). The Curie temperature (range) and hysteresis properties of each investigated flow are, therefore, well-established. The SOH1 drill core covers 240 flows, and the flows selected were ones with sufficiently similar Curie temperatures to allow batch sizes of at least 8 specimens. A summary of the lava flows studied herein (including previous paleointensity estimates) is given in Table 2. Flows with Curie temperatures above $500{ }^{\circ} \mathrm{C}$ were favored on the basis that low-Ti titanomagnetite grains were expected to behave the most similarly to those in Hodgson et al. (2018) in these experiments. The goal was to test the viability of this technique as a paleointensity method by itself, so the rock magnetic properties were used as the first selection criterion for inclusion in this study. The flows and specimens used for each set of experiments were then selected such that the mean expected paleointensity estimates would be around $20 \pm 2 \mu \mathrm{T}$. The expected paleointensity estimates were based on the previous paleointensity data as determined by Teanby et al. (2002) and Gratton et al. (2005). The assessment in Grappone et al. (2020b) suggested that the best paleointensity estimate for a given $\mathrm{SOH} 1$ flow was the mean of the estimates from Teanby et al. (2002) and Gratton et al. (2005) for a given flow. Unlike in Hodgson et al. (2018), we do not have known paleointensity values against which to compare our new data, which is, of course, expected for almost all paleointensity surveys. Further details on the flows selected can be found in Table 1. 
Table 1 Summary of previous paleomagnetic data for flows presented herein

\begin{tabular}{|c|c|c|c|c|c|c|}
\hline \multirow[t]{2}{*}{ Flow } & \multicolumn{3}{|c|}{ Teanby et al. (2002) } & \multicolumn{3}{|c|}{ Gratton et al. (2005) } \\
\hline & $\begin{array}{l}\text { Specimens } \\
\text { (passed/total) }\end{array}$ & Inclination range & $\begin{array}{l}\text { Paleointensity } \\
\text { estimate }\end{array}$ & $\begin{array}{l}\text { Specimens } \\
\text { (passed/total) }\end{array}$ & Curie temp & $\begin{array}{l}\text { Paleointensity } \\
\text { estimate }\end{array}$ \\
\hline 107 & $0 / 1$ & & & $3 / 4$ & 580 & $15.3 \pm 1.0$ \\
\hline 118 & $2 / 2$ & $-0.6^{\circ}-7^{\circ}$ & $21.4 \pm 1.2$ & $0 / 3$ & 570 & \\
\hline 120 & $2 / 3$ & $-2.3^{\circ}-7.9^{\circ}$ & $37.5 \pm 3.3$ & $0 / 4$ & 515 & \\
\hline 123 & $1 / 2$ & $-7.4^{\circ}-2.2^{\circ}$ & 19.5 & $2 / 2$ & 510 & $12.5 \pm 1.2$ \\
\hline 147 & $0 / 1$ & & & $2 / 2$ & 510 & $11.7 \pm 1.7$ \\
\hline 148 & $3 / 3$ & $-2.4^{\circ}-0.8^{\circ}$ & $19.1 \pm 1.6$ & $1 / 2$ & 520 & 12.7 \\
\hline 157 & $2 / 2$ & $-12.9^{\circ}$ to $-0.1^{\circ}$ & $27.3 \pm 1.4$ & $3 / 3$ & 550 & $12.6 \pm 1.3$ \\
\hline 191 & $0 / 3$ & & & $1 / 2$ & 536 & 10.8 \\
\hline 209 & $0 / 1$ & $27.7^{\circ}$ & & $0 / 3$ & 540 & \\
\hline 215 & & & & $1 / 2$ & 580 & 35.7 \\
\hline 224 & $0 / 1$ & & & $4 / 4$ & 560 & $20.3 \pm 3.5$ \\
\hline 225 & $0 / 2$ & $-3.0^{\circ}-5.4^{\circ}$ & & $2 / 3$ & 580 & $10.8 \pm 6.8$ \\
\hline 226 & $2 / 3$ & $-7.1^{\circ}$ to $-3.0^{\circ}$ & $22.2 \pm 4.5$ & $3 / 3$ & 580 & $16.3 \pm 1.2$ \\
\hline 228 & $0 / 1$ & & & $3 / 3$ & 540 & $11.0 \pm 1.6$ \\
\hline 232 & & & & $2 / 2$ & 520 & $13.5 \pm 0.2$ \\
\hline
\end{tabular}

Blank cells indicate no data are available

\section{Rock magnetism}

Hodgson et al. (2018) worked with artificial samples made from naturally occurring magnetite of known magnetic grain size. In order to eventually compare these new results with theirs, the rock magnetic properties of the natural samples need to be well-defined. Specifically, the Curie temperature, the thermoremanent curve shape, and the hysteresis parameters are required. The Curie temperature provided by Gratton et al. (2005) constituted the basis for calculating the temperature range for the experiment. Their Curie temperature estimates were derived from thermoremanent curves using a variable field transition balance. A weakness of the $\mathrm{HiTeCT}$ experiment is that the thermoremanent curves by themselves only provide information on specimens' Curie temperatures and not the specimens' unblocking temperature spectrum, which is a key parameter in the experiments presented herein. Example thermoremanent curves can be found in Fig. 2. The two types of thermoremanent curves observed for the flows in this study can be found in Fig. 2A and B, with the curve type observed in Fig. 2A being more common among the flows tested herein (9/15). The young ages of these rocks mean that, regardless of Curie temperature range, the specimens do not experience substantial thermochemical alteration after a single heating cycle. Thermoremanent curves of the types observed in Fig. 2A and B are typical for specimens that have a narrow and a broad range of Curie temperatures, respectively. Specimens with a wider range of Curie temperatures are, broadly, expected to be less suitable for HiTeCT experiments because a wider range of Curie temperatures often indicates a more varied, complex magnetic mineralogy. The specimens used in Hodgson et al. (2018) had thermoremanent curves more similar to those in Fig. 2A, with narrow Curie temperature ranges.

The hysteresis parameters provide a proxy for magnetic domain states contained in the samples and their stability. A summary of the magnetic properties of the samples studied is provided in Table 2.

Figure 3 contains a bulk domain stability (BDS) plot of these flows' hysteresis parameters (Paterson et al. 2017).

\section{Methods}

The Thellier experiments reported herein are a modified version of the Coe (1967) protocol, which has historically been one of the most used Thellier protocols and was the protocol used in Hodgson et al. (2018). In this variant, each temperature step is first run in a zero-field ( $Z$ step), followed by an in-field step ( $I$ step). In addition, pTRM checks for alteration ( $P$ steps) are added after every other $Z$ step, for a final pattern of $Z_{T} I_{T} Z_{T+1} P_{T-1} I_{T+1}$ where $T$ denotes the temperature step.

The high-temperature Coe-Thellier (HiTeCT) experiment proposed by Hodgson et al. (2018) suggests that no pTRM checks and only temperatures in the range of $[T c-20, T c]$ should be used to get the best paleointensity estimate. One key assumption of the technique is that the unblocking temperature spectra of specimens are clustered close to their Curie temperatures, 

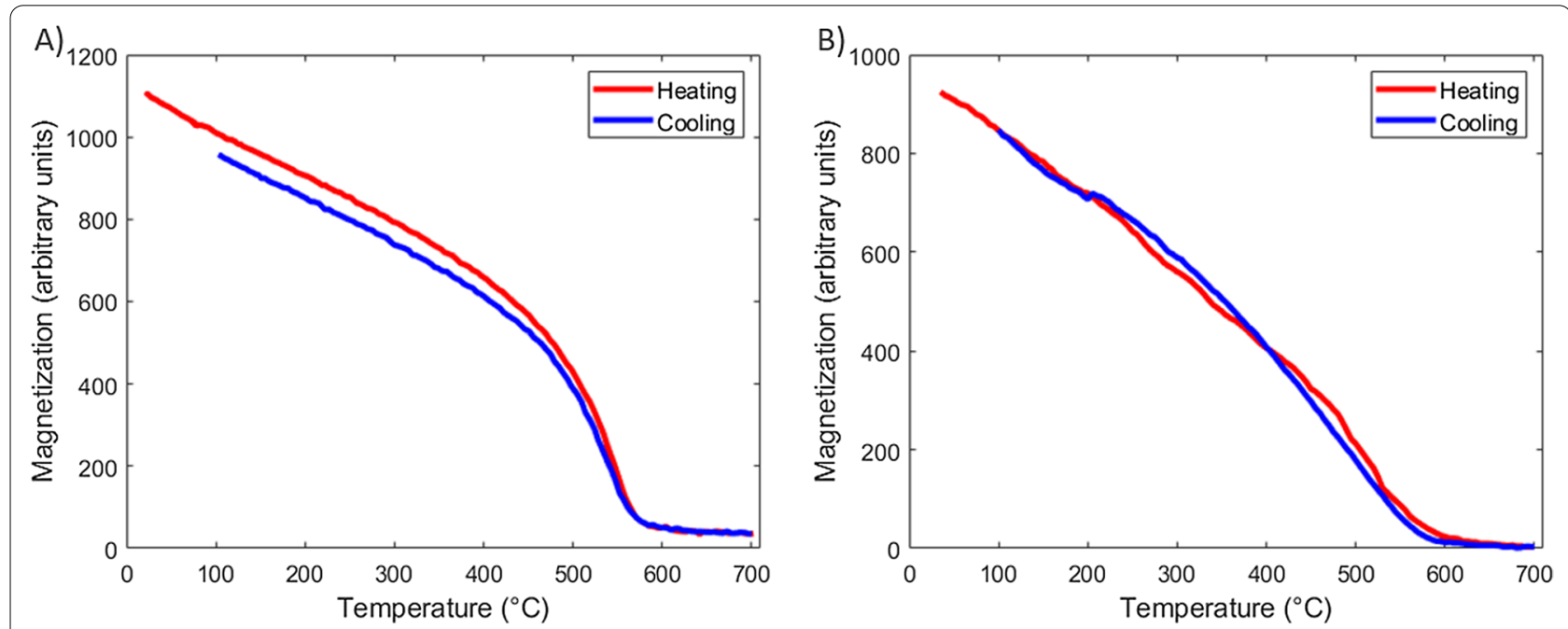

Fig. 2 Example thermoremanent curves characteristic of the flows studied herein. A Contains a single magnetic phase with a narrower primary Curie temperature range. $\mathbf{B}$ Contains an example of a specimen with a broad Curie temperature range

Table 2 Rock magnetic parameters for samples tested herein

\begin{tabular}{lllll}
\hline SOH flow number & Curie temp $\left({ }^{\circ} \mathrm{C}\right)$ & $\frac{M r s}{M \mathbf{s}}$ & $\frac{H c r}{H \boldsymbol{c}}$ & Curve type $^{\mathbf{a}}$ \\
\hline 107 & 580 & 0.34 & 1.88 & $\mathrm{~A}$ \\
118 & 570 & 0.32 & 2.16 & $\mathrm{~B}$ \\
120 & 515 & 0.17 & 2.77 & $\mathrm{~A}$ \\
123 & 510 & 0.15 & 5.34 & $\mathrm{~A}$ \\
147 & 510 & 0.18 & 2.82 & $\mathrm{~B}$ \\
148 & 520 & 0.37 & 1.82 & $\mathrm{~B}$ \\
157 & 550 & 0.28 & 2.27 & $\mathrm{~A}$ \\
191 & 536 & 0.47 & 1.88 & $\mathrm{~A}$ \\
209 & 540 & 0.32 & 2.10 & $\mathrm{~B}$ \\
215 & 580 & 0.51 & 1.56 & $\mathrm{~A}$ \\
224 & 560 & 0.45 & 1.72 & $\mathrm{~B}$ \\
225 & 580 & 0.11 & 8.17 & $\mathrm{~A}$ \\
226 & 580 & 0.12 & 5.82 & $\mathrm{~A}$ \\
228 & 540 & 0.34 & 1.87 & $\mathrm{~B}$ \\
232 & 520 & 0.17 & 3.3 & $\mathrm{~A}$ \\
$\mathrm{LM}^{2}<5^{\mathrm{b}}$ & 569 & 0.18 & 2.13 & - \\
$\mathrm{LM}^{\mathrm{b}} 25-30^{\mathrm{b}}$ & 567 & 0.076 & 3.44 & - \\
\hline
\end{tabular}

${ }^{\mathrm{a}}$ In reference to Fig. 2

${ }^{\mathrm{b}}$ LM6 specimens were tested in Hodgson et al. (2018) and are provided for reference only

All SOH rock magnetic information is taken from the data provided by Gratton et al. (2005)

as defined by thermomagnetic analysis. While this assumption is generally true for stoichiometric magnetite with a narrow grain-size distribution (e.g., those in Hodgson et al. 2018), this assumption often is not the case for natural samples such as those studied herein, which have, in some cases, already been shown to have

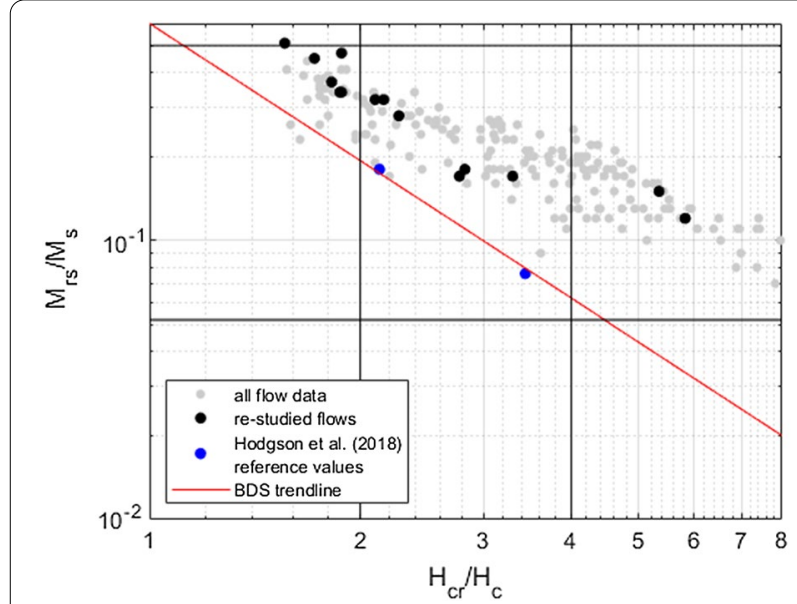

Fig. 3 Bulk domain stability (BDS) plot for the $\mathrm{SOH} 1$ flows studied herein. SOH raw data are taken from Gratton et al. (2005) and Russell (2018). Further information on Hodgson et al. (2018) reference values is provided in Table 2

distributed unblocking temperature spectra (Gratton et al. 2005; Teanby et al. 2002). This technique, therefore, has quite intense requirements and requires extensive rock magnetic data for successful tests. This paper presents both this technique and a series of less extreme variants of the method, with different starting temperatures that range from 200 to $500+{ }^{\circ} \mathrm{C}$, as detailed in Table 3. Non-HiTeCT experiments will be referred to by their starting temperature; e.g., $200 \mathrm{CT}$ is the Coe-Thellier experiment with a starting temperature of $200{ }^{\circ} \mathrm{C}$. 
Table 3 Summary of experiments run for this study

\begin{tabular}{lllll}
\hline Experiment & Temperatures $\left({ }^{\circ} \mathrm{C}\right)$ & Number of steps & Specimens & $\begin{array}{c}\text { Expected } \\
\text { mean } \mathbf{P I} \\
\text { estimate }^{\mathbf{a}}\end{array}$ \\
\hline $200 \mathrm{CT}$ & $T \in[200, T c]$ & 11 & 25 & 21.0 \\
$300 \mathrm{CT}$ & $T \in[300, T c]$ & 11 & 16 & 19.6 \\
$400 \mathrm{CT}$ & $T \in[400, T c]$ & 9 & 18 & 21.8 \\
$500 \mathrm{CT}$ & $T \in[500, T c]$ & 9 & 17 & 20.9 \\
$\mathrm{HiTeCT}$ & $T \in[T C-20, T C+10]$ & 9 or 11 & 19.3 \\
\hline
\end{tabular}

${ }^{a}$ Based on the estimates from Teanby et al. (2002) and Gratton et al. (2005)

The control experiment for this study is the set of CoeThellier experiments that began at an initial temperature of $200{ }^{\circ} \mathrm{C}$ and used temperature steps of $20-50{ }^{\circ} \mathrm{C}$. Experiments were run in 20-40 $\mu \mathrm{T}$ laboratory fields, always applied in the same direction in specimen coordinates: inclination $=90^{\circ}$. The $300 \mathrm{CT}, 400 \mathrm{CT}$, and $500 \mathrm{CT}$ experiments bridge the gap between the typical Coe-Thellier experiment and the Hodgson et al. (2018) high-temperature method. These shortened Coe-Thellier experiments began at elevated temperatures, with initial temperatures of 300,400 , and $500{ }^{\circ} \mathrm{C}$. These four initial temperatures were selected because previous analysis [e.g., Gratton et al. (2005)] has indicated that some SOH1 specimens have overprints that unblock at temperatures around $300{ }^{\circ} \mathrm{C}$.

The HiTeCT experiments began at an initial temperature $20{ }^{\circ} \mathrm{C}$ below the specimen's Curie temperature $\left(T_{\mathrm{C}}\right)$. The experiments ran from $T_{\mathrm{C}}-20{ }^{\circ} \mathrm{C}$ to $T_{\mathrm{C}}+10{ }^{\circ} \mathrm{C}$, outside of the range proposed by Hodgson et al. (2018) to ensure complete demagnetization in the event of any thermochemical alteration. This technique includes pTRM checks, which mitigate the effects of alteration during the experiment. However, a substantial weakness of this technique is that these checks cannot rule out the possibility of alteration occurring during the first (large) temperature step.

The selection criteria used for this study are outlined in Table 4. These selection criteria are based on those used in Grappone et al. (2019) and (2020b) for successful methodology investigations on Hawaiian lavas.

\section{Results}

Across all the Coe-Thellier variants tested herein, a total of 48 specimens passed all selection criteria (51\% pass rate). A summary of the results by experiment type can be found in Table 5. A summary of results by flow can be found in Additional file 1. The highest pass rates came from the lower starting temperatures, with relatively comparable pass rates of $69 \%-72 \%$ being found with the $200 \mathrm{CT}, 300 \mathrm{CT}$, and $400 \mathrm{CT}$ experiments. Increasing the start temperature to $500{ }^{\circ} \mathrm{C}$ for the $500 \mathrm{CT}$ experiment decreased the pass rate substantially to $29 \%$, and the $\mathrm{HiTeCT}$ experiment (with a start temperature up to another $60{ }^{\circ} \mathrm{C}$ higher) further decreased the pass rate to $11 \%$.

Representative Arai plots of the various experiments can be found in Fig. 4. In addition to avoiding overprints, the higher start temperature is expected to provide a more linear Arai plot. A more linear Arai plot can result from both/either reduced thermochemical alteration or reduced non-SD effects. Looking qualitatively at the Arai plots of the specimens that passed, there was no clear difference between the shapes of the $200 \mathrm{CT}, 300 \mathrm{CT}$, or 400CT experiments' Arai plots. There was a slight trend for DRAT (a measure of thermochemical alteration) to decrease as the temperature increased in these experiments. However, DRAT increased for the 500CT and HiTeCT experiments, which is a reasonable consequence of the substantially smaller fraction of the unblocking temperature spectra tested. DRAT relies on normalization by the length of best-fit line. These experiments, the

Table 4 Selection criteria

\begin{tabular}{llllllll}
\hline $\boldsymbol{N}$ & FRAC & $\boldsymbol{\beta}$ & $\boldsymbol{q}$ & MAD $_{\text {ANC }}$ & $\boldsymbol{a}$ & DRAT & $\left|\boldsymbol{K}^{\prime}\right|^{*}$ \\
\hline$\geq 4$ & $\geq 0.35$ & $\leq 0.1$ & $\geq 4$ & $\leq 10$ & $\leq 15$ & $\leq 10 \%$ & - \\
\hline
\end{tabular}

$N$ is the number of data points on the Arai plot. FRAC is a measure of the amount of NRM used. The parameter $\beta$ is a measure of the Arai plot data scatter, $q$ is the quality factor, $M_{A D}{ }_{A N C}$ and $a$ are measures of how well a specimen's direction trends to the origin. DRAT checks for alteration by comparing the error to the length of the best-fit line, and $\left|K^{\prime}\right|$ measures the curvature of the selected portion of the Arai plot. Parameters were calculated according to the standard palaeointensity definitions (Paterson et al. 2014)

${ }^{*}\left|K^{\prime}\right|$ was not used as an explicit selection criterion but will rather be used as a measure of the technique's efficacy. Additional file 1 contains the data suggested for use in any future $\mathrm{SOH}$ meta-analysis 
Table 5 Summary of successful experiments run for this study

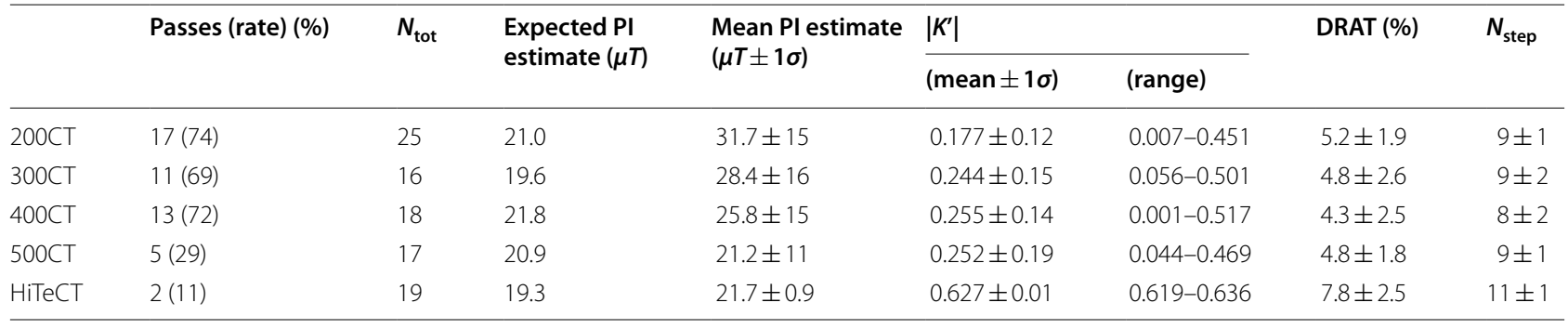

$N_{\text {tot }}$ is the total number of specimens run, PI means paleointensity, $\left|K^{\prime}\right|$ is a measure of curvature of the points selected on an Arai plot, and $N_{\text {step }}$ is the mean number of Arai plot data points selected

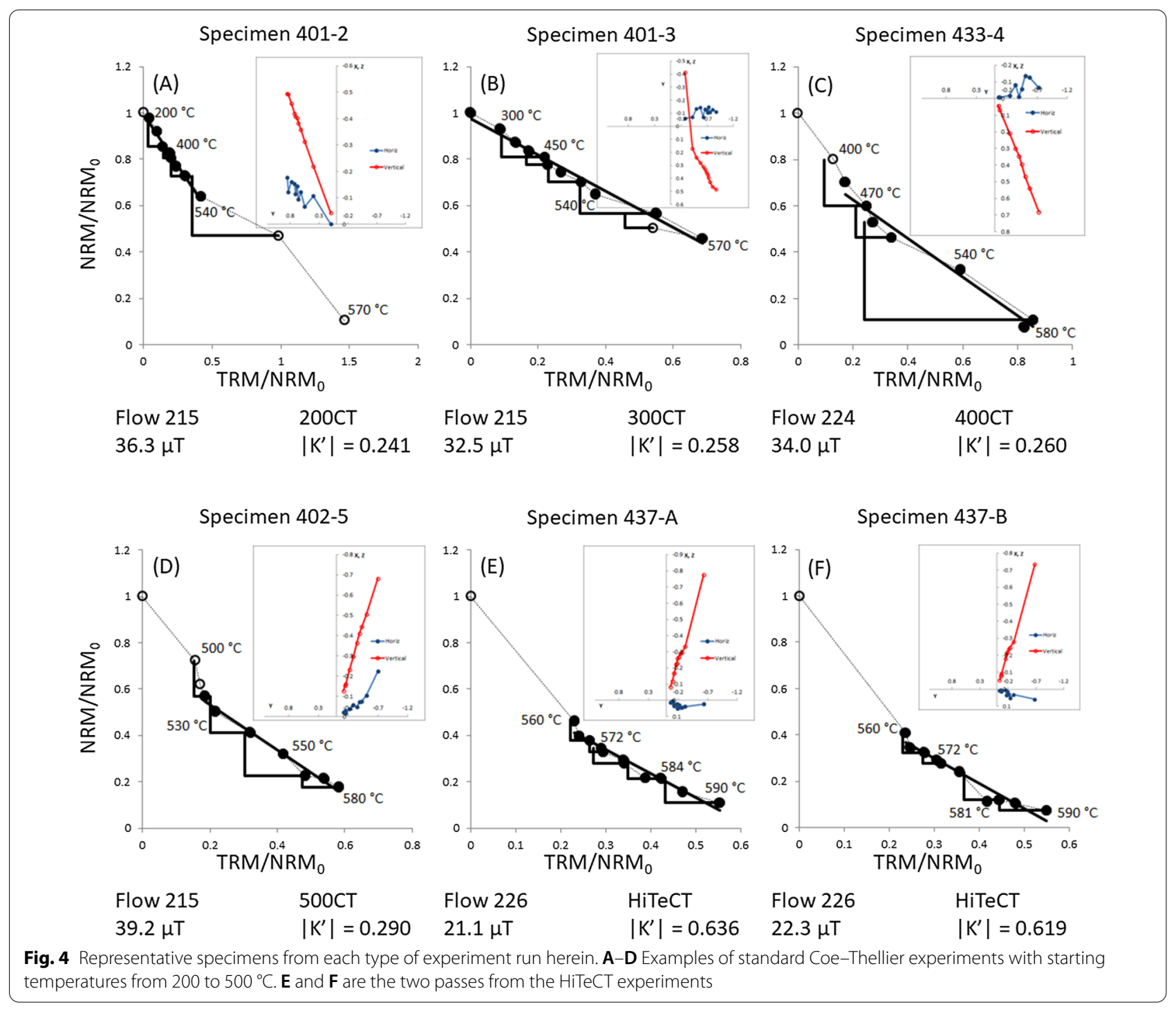




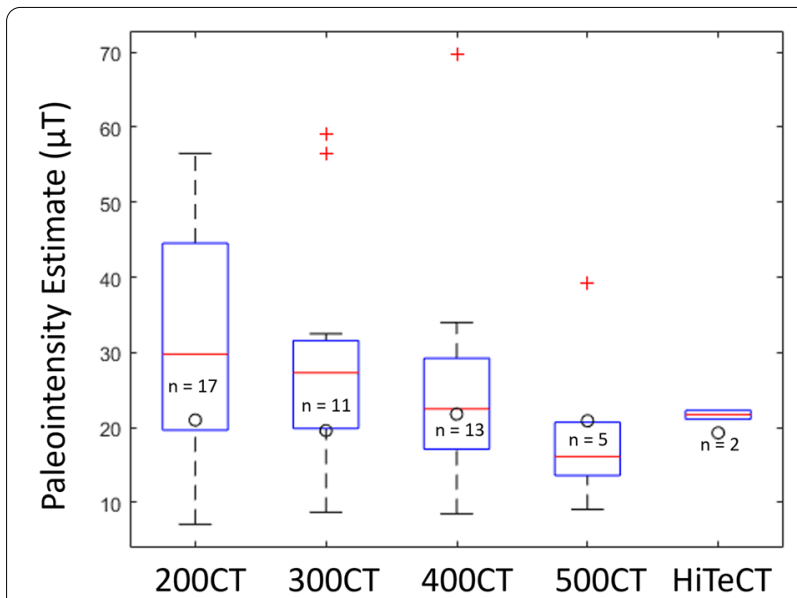

Fig. 5 Boxplot showing mean paleointensity estimate versus experiment type. The blue box shows the boundaries of the first (25\%) and third (75\%) quartiles. The black dashed lines represent the minima and maxima (excluding outliers). Red crosses represent substantial outliers in the data. The black circle is the expected paleointensity estimate, based on the data presented in Table 3. This plot was generated using MATLAB's built-in boxplot script. This figure shows that the median paleointensity estimate decreased as the initial temperature increased from $200^{\circ} \mathrm{C}$ to $500{ }^{\circ} \mathrm{C}$. Table 4 shows that the mean Pl estimate decreased as well

most unconventional presented herein, have qualitatively similar shapes to each other, as observed in Fig. 2D-F.

A summary of pass rates and mean paleointensity estimates are provided in Table 5. A noteworthy trend within the 200-500CT experiments is the apparent decreasing PI estimates with increasing starting temperature. This trend is plotted in Fig. 5 and compared against the expected PI estimate (from Table 3 ). The figure shows a further substantial trend: the $25-75 \%$ paleointensity estimate range decreases with increasing start temperature, whereas the expected paleointensity values remain relatively constant.

Curvature information, quantified by the parameter $|K|$, is reported in Table 5. The lowest mean and maximum curvature values are found from the 200CT experiments, although the large standard deviations mean that this experiment's mean $|K|$ value is not statistically distinct from the $300 \mathrm{CT}, 400 \mathrm{CT}$, or the $500 \mathrm{CT}$ experiments' results $(p=0.21,0.12,0.30$, respectively). The two successful $\mathrm{HiTeCT}$ specimens have the highest curvature of any successful specimen tested herein.

\section{Discussion}

This study obtained a relatively small difference in result quality (as measured using Arai plot selection criteria) from the $200 \mathrm{CT}, 300 \mathrm{CT}$, and $400 \mathrm{CT}$ experiments. According to Hodgson et al. (2018), the higher start temperatures should provide two tangible advantages: less opportunity for low-temperature thermochemical alteration and avoidance of a lowtemperature overprint in the output data. Avoiding thermochemical alteration and reducing the impact of non-single domains grains are the primary goals of many paleointensity methods. This goal covers the microwave paleointensity experiments performed in Gratton et al. (2005) and Grappone et al. (2020b) on these samples, as well as the HiTeCT method tested herein. This effect is apparent here, with the mean DRAT decreasing from $5.2 \%$ (200CT) to $4.3 \%$ (400CT), but the effect remains relatively small. The avoidance of the low-temperature overprint is less clearly visible in the data as no improvement in curvature was observed with increased start temperatures. While the curvature did not decrease as substantially as expected from the data in Hodgson et al. (2018), the mean paleointensity estimates decreased with increased start temperatures. These decreased estimates are largely consistent with the general finding in Grappone et al. (2020b) that the higher-temperature portion of an Arai plot gives lower paleointensity estimates if the specimens have overprints or two-slope Arai plots. The improvements made from increasing the start temperature from $200{ }^{\circ} \mathrm{C}$ to $400{ }^{\circ} \mathrm{C}$ reverse, however, when the start temperatures are increased further.

A recent study by Fabian and Shcherbakov (2020) showed that the onset of low-temperature oxidation begins at temperatures in this same $200-400{ }^{\circ} \mathrm{C}$ range, which means that pTRM checks in this temperature range are less likely to fail. Their findings agree with our result that minimizing the number of heatings in this temperature range, which is often not a temperature range relevant for paleointensity estimates, helps reduce total thermochemical alteration and improve the resulting paleointensity data.

A major limitation to increasing the initial temperature is that higher start temperatures have the potential to introduce more thermochemical alteration before a pTRM check is possible. For moderate starting temperatures, like $200{ }^{\circ} \mathrm{C}$ and $300{ }^{\circ} \mathrm{C}$, the lack of a pTRM check is unlikely to be of substantial concern. However, at higher temperatures $\left(400+{ }^{\circ} \mathrm{C}\right)$, the lack of a low-temperature reference point means that thermochemical alteration caused by, for example, the decomposition of maghemite may not be appropriately detected. Our observations agree with the model presented in Fabian and Shcherbakov (2020), who found that in the $400-500{ }^{\circ} \mathrm{C}$ range, more substantial oxidation was predicted than at lower temperatures, which helps explain why the $400 \mathrm{CT}$ experiments had better initial pTRM checks than the 500CT experiments. 
The experiments that stand out as producing the largest differences are the $500 \mathrm{CT}$ and HiTeCT experiments. The main distinguishing factor for the 500CT experiment from those with lower start temperatures is its substantially lower pass rate (due to low FRAC and high $\beta$ ), but those that pass have comparable DRAT and curvature. The HiTeCT method, on the other hand, failed to improve either the pass rate or the Arai plot curvature. These experiments rely on the assumption that the unblocking temperatures of a specimen's grains are generally clustered near the specimen's Curie temperature, which is not the case here or, indeed, for samples from many rock units. Both these experiments lack any means for checking thermochemical alteration occurring between the NRM and $500+{ }^{\circ} \mathrm{C}$. Further, the small temperature steps, while reproducible (Hodgson et al. 2018), fail to monotonically unblock the specimens. Since each temperature step only marginally increases the grains that can be unblocked, the demagnetization and remagnetization 'levers' do not change substantially, which means that the influence of small errors in orientation and handling of the specimen is, proportionally, larger on the change between each step. The HiTeCT approach fails to monotonically unblock specimens and lacks checks for alteration. Thus, we conclude that the HiTeCT approach is unsuitable for natural specimens that have less ideal rock magnetic properties than the artificial specimens tested in Hodgson et al. (2018).

\section{Conclusions}

In this paper, variants of the Coe-Thellier paleointensity method were tested on Hawaiian lavas from the Scientific Observation Hole 1. Higher initial temperatures correlated with marginally decreased mean paleointensity estimates, but no substantial change in success rate was observed when the start temperature was increased from $200{ }^{\circ} \mathrm{C}$ to $300{ }^{\circ} \mathrm{C}$ or $400{ }^{\circ} \mathrm{C}$. For specimens with start temperatures of $500+{ }^{\circ} \mathrm{C}$ (temperatures near the Curie temperature of their main magnetic carrier, magnetite), however, the success rate dropped substantially. No clear improvement in the quality of the Arai plot data was found, contradicting previous experiments that used artificially created specimens. For future paleointensity experiments, this paper shows that higher start temperatures can be used to avoid low-temperature Arai plot components that are expected to be the result of a magnetic overprint. The higher start temperatures, however, did not prevent non-SD curvature from influencing the Arai plots.
Abbreviations

200CT: $200^{\circ} \mathrm{C}$ Coe-Thellier experiment; $300 \mathrm{CT}$ : $300^{\circ} \mathrm{C}$ Coe-Thellier experiment; 400CT: $400{ }^{\circ} \mathrm{C}$ Coe-Thellier experiment; $500 \mathrm{CT}$ : $500^{\circ} \mathrm{C}$ Coe-Thellier experiment; HiTeCT: High-temperature Coe-Thellier; MAD $_{\text {anc }}$ : Mean angular deviation (anchored); MD: Multi-domain; NRM: Natural remanent magnetization; PI: Paleointensity; pTRM: Partial thermoremanent magnetization; SD: Single domain; $\mathrm{SOH} 1$ : Scientific Observation Bore Hole 1; $\mathrm{T}_{c}$ : Curie temperature; TRM: Thermoremanent magnetization.

\section{Supplementary Information}

The online version contains supplementary material available at https://doi. org/10.1186/s40623-021-01558-2.

Additional file 1: Table S1. Summary of Arai plot statistics from successful paleointensity experiments.

\section{Acknowledgements}

JMG thanks Dr Mimi Hill, Prof John Shaw, Prof Wyn Williams, and Prof Richard Worden, who all read previous versions of this manuscript as part of his PhD thesis (Grappone 2020). We thank Prof Valera Shcherbakov and Prof Huapei Wang for reviewing this manuscript.

\section{Authors' contributions}

JMG conceived of the project; collected the 200CT, 300CT, 400CT, 500CT and some of the HiTeCT data; and wrote and edited the paper. JMR collected the rest of the HiTeCT data and provided editing assistance. AJB provided mentorship to JMG and JMR and helped edit every draft of this manuscript. All authors read and approved the final manuscript.

\section{Funding}

JMG acknowledges support from the NERC EAO Doctoral Training Programme (Grant NE/L002469/1; studentship 1793213) and the Duncan Norman Research Scholarship. Both AJB and JMG further acknowledge funding from The Leverhulme Trust (RLA-2016-080).

\section{Availability of data and materials}

All paleointensity data will be available on the MaglC database at earthref.org/ MaglC/19373.

\section{Declarations}

\section{Competing interests}

The authors declare no competing interests.

Received: 1 October 2021 Accepted: 9 December 2021

Published online: 20 December 2021

\section{References}

Biggin AJ, Paterson GA (2014) A new set of qualitative reliability criteria to aid inferences on palaeomagnetic dipole moment variations through geological time. Front Earth Sci. https://doi.org/10.3389/feart.2014.00024

Biggin AJ, Thomas DN (2003) Analysis of long-term variations in the geomagnetic poloidal field intensity and evaluation of their relationship with global geodynamics. Geophys J Int 152(2):392-415. https://doi.org/10. 1046/j.1365-246X.2003.01849.x

Butler RF (1992) Paleomagnetism: magnetic domains to geologic terranes.

Coe RS (1967) Determination of paleo-intensities of earths magnetic field with emphasis on mechanisms which could cause non-ideal behavior in Thellier's method. J Geomagn Geoelectr 19(3):157-179

Coe RS, Riisager J, Plenier G, Leonhardt R, Krasa D (2004) Multidomain behavior during Thellier paleointensity experiments: results from the 1915 Mt. Lassen Flow. Phys Earth Planet Interiors 147(2-3):141-153

Dunlop DJ, Ozdemir O (2001) Beyond Neel's theories: thermal demagnetization of narrow-band partial thermoremanent magnetizations. Phys Earth Planet Inter 126(1-2):43-57 
Dunlop DJ, Zhang BX, Ozdemir O (2005) Linear and nonlinear Thellier paleointensity behavior of natural minerals. J Geophys Res Solid Earth. https:// doi.org/10.1029/2004JB003095

Fabian K, Shcherbakov VP (2020) The magnetization of the ocean floor: stress and fracturing of titanomagnetite particles by low-temperature oxidation. Geophys J Int 221(3):2104-2112

Grappone JM, Biggin AJ, Hill MJ (2019) Solving the mystery of the 1960 Hawaiian lava flow: implications for estimating Earth's magnetic field. Geophys J Int 218(3):1796-1806. https://doi.org/10.1093/gji/ggz252

Grappone JM (2020a) Prototyping the next generation of versatile paleomagnetic laboratory. Doctor of Philosophy: University of Liverpool, p. 341.

Grappone JM, Biggin AJ, Barrett TJ, Hill MJ, Sprain CJ (2020b) Comparison of thermal and microwave paleointensity estimates in specimens displaying non-ideal behavior in Thellier-style paleointensity experiments. J Geophys Res Solid Earth. https://doi.org/10.1029/2020JB019802

Gratton MN, Shaw J, Herrero-Bervera E (2005) An absolute palaeointensity record from $\mathrm{SOH} 1$ lava core, Hawaii using the microwave technique. Phys Earth Planet Inter 148(2-4):193-214

Hodgson E, Grappone JM, Biggin AJ, Hill MJ, Dekkers MJ (2018) Thermoremanent behavior in synthetic samples containing natural oxyexsolved titanomagnetite. Geochem Geophys Geosyst 19(6):1751-1766. https:// doi.org/10.1029/2017GC007354

Koenigsberger J (1936) Die Abhängigkeit Der Natürlichen Remanenten Magnetisierung Bei Eruptivgesteinen Von Deren Alter Und Zusammensetzung. Beitrag Angewandten Geophysik 5:193-246

Levi S (1977) Effect of magnetite particle-size on paleointensity determinations of geomagnetic-field. Phys Earth Planet Inter 13(4):245-259

Nagata T, Momose K, Arai Y (1963) Secular variation of geomagnetic total force during last 5000 years. J Geophys Res 68(18):5277-5281

Paterson GA, Tauxe L, Biggin AJ, Shaar R, Jonestrask LC (2014) On improving the selection of Thellier-type paleointensity data. Geochem Geophys Geosyst 15(4):1180-1192

Paterson GA, Muxworthy AR, Yamamoto Y, Pan Y (2017) Bulk magnetic domain stability controls paleointensity fidelity. Proc Natl Acad Sci 114(50):13120-13125

Riisager P, Riisager J (2001) Detecting multidomain magnetic grains in Thellier palaeointensity experiments. Phys Earth Planet Inter 125(1-4):111-117

Russell JM (2018) Thermoremanent behaviour in natural samples. Bachelor of Science: University of Liverpool

Shcherbakov VP, Shcherbakova VV (2001) On the suitability of the Thellier method of palaeointensity determinations on pseudo-single-domain and multidomain grains. Geophys J Int 146(1):20-30

Shcherbakova V, Shcherbakov VP, Heider F (2000) Properties of partial thermoremanent magnetization in pseudosingle domain and multidomain magnetite grains. J Geophys Res Solid Earth 105(B1):767-781

Teanby N, Laj C, Gubbins D, Pringle M (2002) A detailed palaeointensity and inclination record from drill core $\mathrm{SOH} 1$ on Hawaii. Phys Earth Planet Inter 131(2):101-140

Thellier E, Thellier O (1959) Sur l'intensité du champ magnétique terrestre dans le passé historique et géologique. Ann Géophys 15:285-376

Xu S, Dunlop DJ (2004) Thellier paleointensity theory and experiments for multidomain grains. J Geophys Res Solid Earth. https://doi.org/10.1029/ 2004JB003024

\section{Publisher's Note}

Springer Nature remains neutral with regard to jurisdictional claims in published maps and institutional affiliations.

\section{Submit your manuscript to a SpringerOpen ${ }^{\odot}$ journal and benefit from:}

- Convenient online submission

- Rigorous peer review

- Open access: articles freely available online

- High visibility within the field

- Retaining the copyright to your article

Submit your next manuscript at $\boldsymbol{\nabla}$ springeropen.com 